\title{
The Relation between Catches of Mackerel and the Surface Temperature in situ.
}

\author{
By
}

J. R. Lumby,

Fisheries Laboratory, Lowestoft.

With Charts I-III, and 3 Tables in the Text.

THE short investigation here described was made in March and April, 1922, during the spring mackerel fishing season off the Cornish coast, in order to discover whether the opinion of Skipper Wylie, of Lowestoft, (drifter, Realize) was justified. In his opinion the best catches of mackerel were made wherever his thermometer showed him a sea surface temperature higher than that of the neighbouring water.

About a dozen drifter skippers, who volunteered to undertake the work, were given thermometers, graduated in $1 / 5^{\circ} \mathrm{C}$. (about 20 graduations per cm.) and forms upon which to record their observations, and were shown how to take a surface sample and read its temperature. These thermometers were not very suitable, since the range was too great, and therefore the scale too small. They also suffered from the defect that the mercury thread easily become broken, and if the detached portion ran down into the bulb at the top of the tube, it was difficult to ensure that all the mercury came out again, and that the thread made a proper joint.

The forms used (p. 241) were based upon the log books used during the investigations on pelagic fishes from 1895 to $1911^{*}$ (Russell, 1915). It was hoped that sufficient data would be collected in the course of a month, but, although the experiment was extended into April, only 32 records are available, covering the period 9th March-19th April.

These records are tabulated in Table 1 . In those cases where the temperatures at the times of shooting and hauling differed, both the values are given, but their mean has been used in computing averages.

The first and second columns refer to the position of hauls shown on the charts. The hauls between the 9 th and 15th March have been plotted on Chart I, between 19th and 30th March on Chart II, and between 4th and 19th April on Chart III. 1915 . 
An inspection of the charts seems to show a movement of the fishing away from the Bristol Channel and Wolf Grounds after the middle of March, after which date nearly all the records are from grounds west of

MACKEREL AND TEMPERATURE, 1922.

TABLE I.

\begin{tabular}{|c|c|c|c|c|c|c|c|c|c|c|c|}
\hline है & 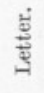 & Date. & $\begin{array}{l}{ }^{\circ} \mathrm{C} \text {. } \\
\text { Temp. }\end{array}$ & Wind. & & Sea. & 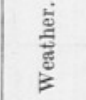 & Water Colour. & Cateh. & Nets. & 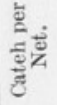 \\
\hline \multirow[t]{13}{*}{ I } & A & 9.3 .22 & 10 & N. & 3 & 3 & b.c. & Lt. gn. & 1,200 & 200 & $6 \cdot 0$ \\
\hline & B & , & $9 \cdot 8$ & N.N.W. & 2 & 3 & b.c. & Lt. gn. & 300 & 220 & $1 \cdot 4$ \\
\hline & $\mathrm{C}$ & ," & 9 & N.N.W. & 3 & 3 & b.c. & Clear lt. gn. & 600 & 90 & $6 \cdot 7$ \\
\hline & D & 10.3 .22 & $\begin{array}{l}9 \cdot 8 \\
9 \cdot 7\end{array}$ & N.N.E. & 4 & 4 & b.c. & Clear ]t. gn. & 200 & 220 & .9 \\
\hline & E & 9.3 .22 & - & N. & 2 & 3 & b.c.p. & - & 150 & 207 & \\
\hline & F & 10.3 .22 & - & N.E. & 4 & 4 & & 一 & 2,500 & 207 & $12 \cdot 1$ \\
\hline & $\mathrm{G}$ & 11.3 .22 & $\begin{array}{l}10 \cdot 1 \\
10 \cdot 0\end{array}$ & N.N.E. & $2-3$ & $2-3$ & b.c. & Green & 200 & 207 & 1.0 \\
\hline & $\mathrm{H}$ & & 9 & N. $\times$ E. & 3 & 3 & b.c. & Clear lt. gn. & 500 & 200 & $2 \cdot 5$ \\
\hline & $\mathbf{J}$ & 12.3 .22 & $9 \cdot 8$ & E.N.E. & 3 & 3 & b. & Green & 800 & 207 & $3 \cdot 9$ \\
\hline & K & 13.3 .22 & 9 & E N.E. & 3. & 3 & b.c. & Green & 300 & 200 & $1 \cdot 5$ \\
\hline & $\mathrm{L}$ & 14.3 .22 & $\begin{array}{l}9 \cdot 8 \\
9 \cdot 6\end{array}$ & E.S.E. & 3 & 3 & b.c. & Lt. gn. & 2,000 & 200 & $10 \cdot 0$ \\
\hline & M & 15.3 .22 & $10 \cdot 0$ & E.S.E. & 4 & 4 & b.c.m. & Thick lt. gn. & 7,000 & 200 & $35 \cdot 0$ \\
\hline & $\mathrm{N}$ & & $9 \cdot 8$ & E.S.E. & 4 & 4 & & Clear lt. gn. & 1,500 & 90 & $16 \cdot 7$ \\
\hline \multirow[t]{11}{*}{ II } & A & 19.3.2. & $10 \cdot 0$ & N.E. & 3 & 3 & b.c.m. & Dk. gn. & 10,000 & 200 & $50 \cdot 0$ \\
\hline & B & ", & $\left\{\begin{array}{r}16 \cdot 0 \\
9 \cdot 8\end{array}\right.$ & N.E. $\times$ N. & 3 & 3 & & $\begin{array}{l}\text { Rather thick } \\
\text { med. dk. gn. }\end{array}$ & 3,000 & 200 & $15 \cdot 0$ \\
\hline & $\mathrm{C}$ & 20.3 .22 & $9 \cdot 6$ & N.E. $\times$ N. & 4 & 4 & p.s. & $\begin{array}{c}\text { Thick med. } \\
\text { dk. }\end{array}$ & 4,000 & 200 & $20 \cdot 0$ \\
\hline & D & 23.3.22 & $8 \cdot 4$ & N.N.E. & 3 & 4 & & Clear lt. gn. & 4,000 & 90 & $44 \cdot 4$ \\
\hline & $\mathrm{E}$ & 24.3 .22 & $10 \cdot 5$ & N.W. & 3 & 3 & b.c.q. & Thick lt. gn. & 600 & 220 & $2 \cdot 7$ \\
\hline & $\mathrm{F}$ & 26.3 .22 & $9 \cdot 7$ & N.W. & $4-5$ & $4-5$ & b.c.q. & - & 1,000 & 207 & $4 \cdot 8$ \\
\hline & G & 28.3 .22 & $9 \cdot 5$ & N.E. $\times$ E. & 3 & 4 & b.c.q. & - & 2,000 & 207 & $9 \cdot 7$ \\
\hline & $\mathrm{H}$ & & $8 \cdot 4$ & N.E. $\times$ E. & 3 & 4 & b.c. & Clear lt. gn. & 1,200 & 90 & $13 \cdot 3$ \\
\hline & $\mathrm{J}$ & 29.3.22 & $10 \cdot 2$ & S.S.E. & 2 & 2 & b.c. & Clear lt. gn. & 800 & 90 & $8 \cdot 9$ \\
\hline & $\mathrm{K}$ & 30.3 .22 & $9 \cdot 4$ & S.S.W. & 2 & 2 & b.c. & Med. dk. & Nil & 99 & -1 \\
\hline & $\mathrm{L}$ & & $9 \cdot 8$ & N.N.W. & 4 & 4 & c.q. & Lt. gn. & 1,800 & 210 & $8 \cdot 6$ \\
\hline \multirow[t]{8}{*}{ III } & A & 4.4 .22 & $9 \cdot 4$ & W.N.W. & 3 & 4 & b. & Clear slate & 1,400 & 90 & $15 \cdot 6$ \\
\hline & B & , & $\left\{\begin{array}{l}10 \cdot 0 \\
10 \cdot 3\end{array}\right.$ & W.S.W. & 3 & 3 & b.c. & Lt. gn. & 2,000 & 209 & $9 \cdot 6$ \\
\hline & $\mathrm{C}$ & 5.4 .22 & $\begin{array}{l}10 \cdot 5 \\
10 \cdot 3\end{array}$ & W.S.W. & 2 & 2 & b.c. & Lt. gn. & 3.000 & 209 & $14 \cdot 4$ \\
\hline & D & & $9 \cdot 6$ & W.N.W. & 3 & 2 & b.c. & Clear lt. gn. & 2.600 & 90 & $28 \cdot 9$ \\
\hline & E & 11.4 .22 & $10 \cdot 0$ & S.S.W. & 2 & 2 & c. & Lt. gn. & 150 & 90 & $1 \cdot 7$ \\
\hline & $F$ & 13.4 .22 & $9 \cdot 2$ & E. $\times$ N. & 2 & 4 & c.p. & Clear lt. gn. & 450 & 90 & $5 \cdot 0$ \\
\hline & G & 18.4 .22 & $10 \cdot 0$ & N. & 2 & 2 & b. & Clear lt. gn. & Nil & 90 & 一 \\
\hline & $\mathrm{H}$ & 19.4 .22 & $10 \cdot 0$ & N. $\times$ E. & 2 & 2 & b & Clear & $\begin{array}{l}\text { Not } \\
\text { stated }\end{array}$ & 90 & - \\
\hline
\end{tabular}

the Scilly Islands. This is in consonance with the results of the Log Book investigations above referred to.

The times at which boats were accustomed to shoot and haul were all approximately the same, so that it is unnecessary to consider diurnal 
variation in the discussion of the temperatures. The routine followed was to shoot about an hour before dark, viz. 5 to 6 p.m., and to haul about midnight.

TABLE II.

\section{"SEVEN STONES."}

\begin{tabular}{|c|c|c|c|c|c|}
\hline \multirow{2}{*}{ Date. } & \multirow{2}{*}{ Time. } & \multicolumn{2}{|c|}{ Temp. ${ }^{\circ} \mathrm{C}$. } & \multirow{2}{*}{$\begin{array}{c}\text { Salinity } \\
\% 0^{\circ}\end{array}$} & \multirow{2}{*}{ Wind. } \\
\hline & & Sea. & Air. & & \\
\hline 1922 & & & & & \\
\hline March 1st & 4 p.m. & $9 \cdot 8$ & $6 \cdot 7$ & $35 \cdot 17$ & - \\
\hline 5 th & 5.30 p.m. & $10 \cdot 2$ & $11 \cdot 7$ & $\cdot 24$ & - \\
\hline 9th & 9 a.m. & $9 \cdot 4$ & $11 \cdot 7$ & $\cdot 30$ & N.N.W. \\
\hline 13 th & 1.30 p.m. & $9 \cdot 7$ & $9 \cdot 4$ & $\cdot 23$ & E. \\
\hline 17 th & 5 p.m. & $9 \cdot 8$ & $9 \cdot 4$ & $\cdot 28$ & S.E. \\
\hline 21 st & 10 a.m. & $9 \cdot 4$ & - & $\cdot 22$ & - \\
\hline 25th & noon & $9 \cdot 3$ & $7 \cdot 8$ & .23 & N.N.W. \\
\hline 29th & 10 a.m. & $9 \cdot 5$ & $7 \cdot 8$ & $\cdot 21$ & S.E. \\
\hline April 1st & 2 p.m. & $9 \cdot 1$ & $7 \cdot 2$ & $\cdot 23$ & E.N.E. \\
\hline 5 th & 9 a.m. & $9 \cdot 6$ & - & $\cdot 35$ & S.W. \\
\hline 9 th & noon & $9 \cdot 7$ & $10 \cdot 0$ & $\cdot 37$ & $\mathrm{~N}$. \\
\hline 13th & 4 p.m. & $10 \cdot 3$ & $8 \cdot 3$ & $\cdot 26$ & S.E. \\
\hline 17th & 5 p.m. & $9 \cdot 7$ & $7 \cdot 8$ & $\cdot 24$ & N.E. \\
\hline $21 \mathrm{st}$ & 8.30 a.m. & $9 \cdot 8$ & $10 \cdot 0$ & $\cdot 26$ & $\mathrm{~N}$. \\
\hline 25 th & noon & $9 \cdot 6$ & $10 \cdot 0$ & $\cdot 28$ & $\mathrm{~N}$. \\
\hline 29th & 3 p.m. & $9 \cdot 3$ & $6 \cdot 7$ & $\cdot 24$ & 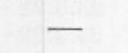 \\
\hline
\end{tabular}

TABLE III.

MEAN MONTHLY VALUES AT “SEVEN STONES."

\begin{tabular}{l|r|r|r|r}
\hline \multicolumn{1}{c|}{ 1922. } & $\begin{array}{c}\text { Temp. } \\
{ }^{\circ} \mathrm{C} .\end{array}$ & Anomaly. & $\begin{array}{r}\text { Salinity. } \\
\%\end{array}$ & Anomaly. \\
\cline { 2 - 2 } \cline { 5 - 5 } January & $11 \cdot 1$ & $+1 \cdot 0$ & $35 \cdot 34$ & $+\cdot 08$ \\
February & $10 \cdot 0$ & $+0 \cdot 5$ & $\cdot 30$ & $+\cdot 06$ \\
March & $9 \cdot 6$ & $+0 \cdot 5$ & $\cdot 24$ & $+\cdot 01$ \\
April & $9 \cdot 7$ & $+0 \cdot 1$ & $\cdot 27$ & $+\cdot 04$ \\
May & $11 \cdot 4$ & $+0 \cdot 7$ & $\cdot 23$ & $+\cdot 01$ \\
\hline
\end{tabular}

Taking the records as a whole, the average temperature corresponding to catches of 10 and over per net is $9 \cdot 6^{\circ} \mathrm{C}$., and that corresponding to catches of less than 10 is $9 \cdot 7^{\circ} \mathrm{C}$. It is of interest to note here that the mean 
monthly temperatures at the "Seven Stones" for March and April are $9 \cdot 6$ and $9 \cdot 7^{\circ} \mathrm{C}$. respectively (Table III). As regards the average figures from the records, this difference of $1 / 10^{\circ} \mathrm{C}$. is scarcely significant, taking into consideration the liability of the observations to error : for example, for two adjacent hauls, Chart I, A and $\mathrm{C}$, on the same date, temperatures of $10^{\circ}$ and $9^{\circ}$ are recorded.

Apparently, then, only very small temperature changes seem to have occurred over the whole area. The "Seven Stones" observations (Table II) were taken at varying times during the day, yet, there, the

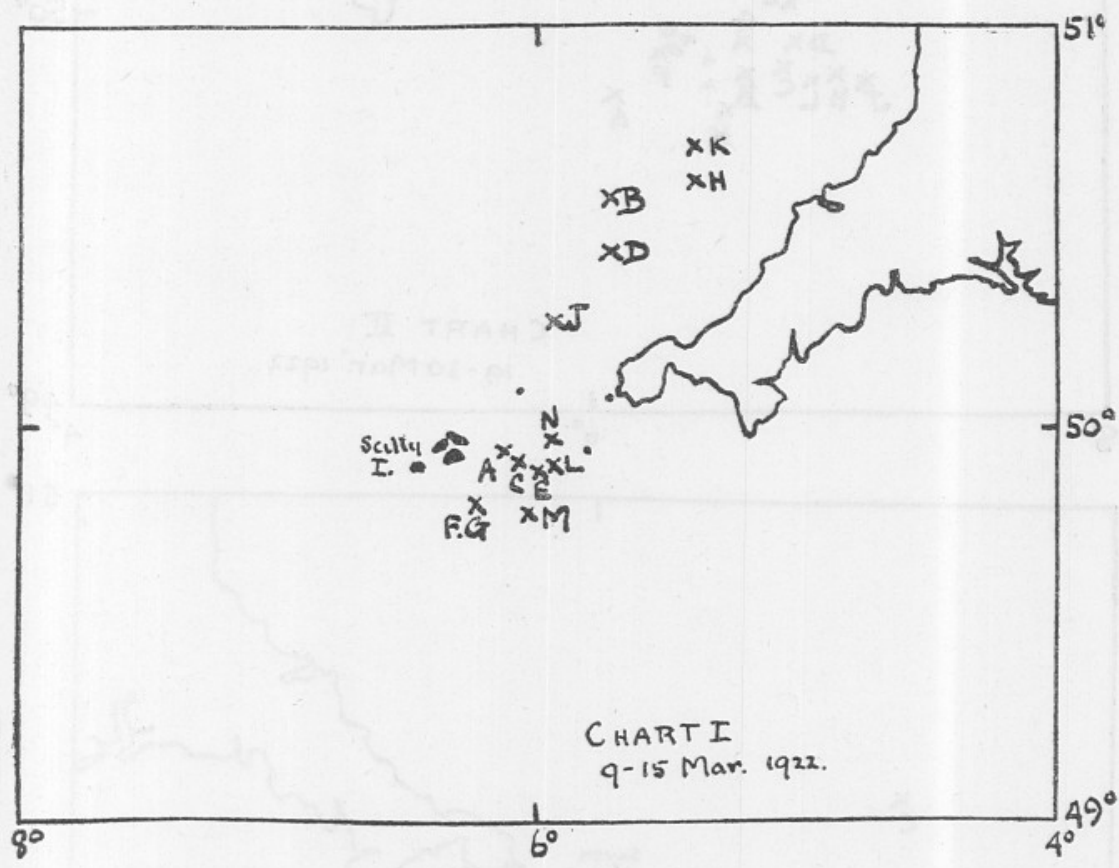

Chart I illustrating Table I.

difference between the highest and lowest values for the whole period, March-April, is only $1 \cdot 2^{\circ} \mathrm{C}$.

In Chart I the records of hauls fall into two groups (1) from the Wolf Ground, and (2) from N.E. of Longships. The average temperature of group 1 is $9.8^{\circ} \mathrm{C}$., and the average catch per net 11.0 ; for group 2 the averages are, temperature $9 \cdot 5^{\circ}$, and catch $2 \cdot 0$.

Again, it is doubtful whether the temperature difference between the two groups, although it amounts to $\frac{1}{4}^{\circ} \mathrm{C}$., can be taken as real, since the data are too scanty. As far as may be judged from this difference, and from the trend of the salinity observed at Seven Stones, it may well have 

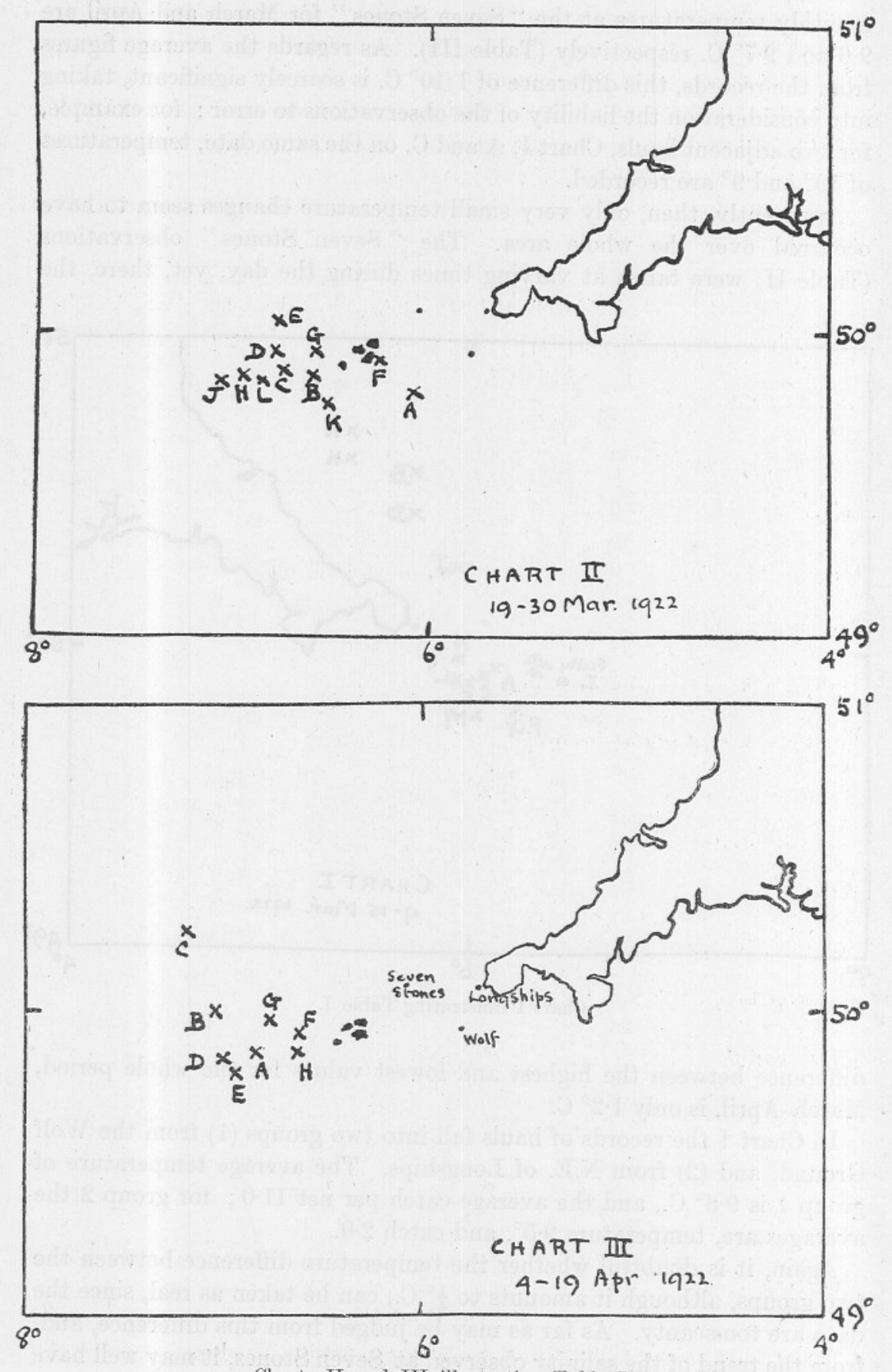

Charts II and III illustrating Table I. 
been the case that colder water was driven under the influence of the strong north-easterly winds prevailing then from the Bristol Channel down the north coast of Cornwall.

To sum up, it is clear that the data are insufficient to use as a basis for reliable differentiation, but generally it appears that high temperatures are not necessarily related to good catches.

The help and advice of the Director and Staff of the Plymouth Laboratory are gratefully acknowledged.

MINISTRY OF AGRICULTURE AND FISHERIES.

MACKEREL FISHERY INVESTIGATIONS, 1922.

Name of Vessel

Port Letters and No.

Date

Time of Shooting

Time of Hauling

Position

Temperature of sea at shooting

Temperature of sea at hauling

Wind direction

Force

Sea disturbance

Weather

Colour of Water

Smell of Water

Kind of Fish

Number of Nets

Mesh

Total Catch

Remarks

(Signature)

Please return to the Collector of Fishery Statistics, Newlyn. NEW SERISS, - VoL. XIII. No. 1. DECEMBER, 1923. 
To take the temperature of the sea.

It is requested that a uniform method may be adopted. A suitable clean bucket is hove from a position of the ship well clear of all waste discharges. The bucket having been well rinsed by two or three successive casts, in order to clean it and bring it to sea temperature, a final sample is drawn and the temperature taken. The thermometer having been inspected, is immersed and used to stir the sample until the reading is constant, To read the height of the mercury column, the thermometer, with the bulb still immersed, is held in such a position that it is perpendicular to the direction of sight. The temperature should be read to the nearest graduation mark. The graduations between the whole numbers are $\cdot 2, \cdot 4, \cdot 6$ and $\cdot 8$. The reading is noted at once to avoid errors due to forgetfulness.

Scale of Wind.
1. Calm.
3. Moderate breeze.
5. Gale.
2. Light breeze.
4. Strong wind.
6. Storm.

Scale of Sea Disturbance.
1. Calm.
3. Moderate.
5. Very rough.
2. Slight.
4. Rough.
6. Tremendous sea.

Scale of weather.
b. Blue sky.
b.c. Partly clouded.
o. Overcast.
c. Nearly all clouded.
p. Passing showers.
d. Drizzle.
r. Steady rain.
f. Fog.
s. Snow.
$f$. Very foggy.
rs. Sleet.
h. Hail.
t. Thunder
1. Lightning.
u. Threatening.
m. Mist.
w. Dew.
x. Frost.

Scale of Colour of Water.

Very dark.

Medium dark.

Light green.

Yellow-green.

Mention if thick or clear.

Scale of Smell.

No smell.

Little smell.

Stinking. 